\title{
(6) OPEN ACCESS \\ Does age affect surgical outcomes in patients with degenerative cervical myelopathy? Results from the prospective multicenter AOSpine International study on 479 patients
}

\author{
Hiroaki Nakashima, ${ }^{1,2}$ Lindsay A Tetreault, ${ }^{1,3}$ Narihito Nagoshi, ${ }^{1,4}$ Aria Nouri, ${ }^{1,3}$ \\ Branko Kopjar, ${ }^{5}$ Paul M Arnold, ${ }^{6}$ Ronald Bartels, ${ }^{7}$ Helton Defino, ${ }^{8}$ Shashank Kale, ${ }^{9}$ \\ Qiang Zhou, ${ }^{10}$ Michael G Fehlings ${ }^{1,3}$
}

For numbered affiliations see end of article.

\section{Correspondence to}

Dr Michael G. Fehlings, Suite 4W449, Toronto Western Hospital, 399 Bathurst St, Toronto, Ontario Canada M5T 2S8;

Michael.Fehlings@uhn.on.ca

HN, LAT authors contributed equally to this work.

Received 20 April 2015 Accepted 16 July 2015 Published Online First 29 September 2015

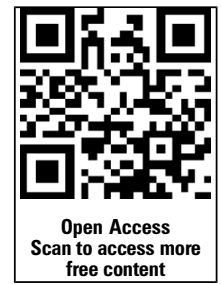

CrossMark

\footnotetext{
To cite: Nakashima $\mathrm{H}$ Tetreault LA, Nagoshi $N$, et al. I Neurol Neurosurg Psychiatry 2016;87: 734-740.
}

\section{ABSTRACT}

Background In general, older patients with degenerative cervical myelopathy (DCM) are felt to have lower recovery potential following surgery due to increased degenerative pathology, comorbidities, reduced physiological reserves and age-related changes to the spinal cord. This study aims to determine whether age truly is an independent predictor of surgical outcome and to provide evidence to guide practice and decisionmaking.

Methods A total of 479 patients with DCM were prospectively enrolled in the CSM-International study at 16 centres. Our sample was divided into a younger group ( $<65$ years) and an elderly ( $\geq 65$ years) group. $A$ mixed model analytic approach was used to evaluate differences in the modified Japanese Orthopaedic Association (mJOA), Nurick, Short Form-36 (SF-36) and Neck Disability Index (NDI) scores between groups. We first created an unadjusted model between age and surgical outcome and then developed two adjusted models that accounted for variations in (1) baseline characteristics and (2) both baseline and surgical factors. Results of the 479 patients, 360 (75.16\%) were $<65$ years and $119(24.84 \%)$ were $\geq 65$ years. Elderly patients had a worse preoperative health status $(p<0.0001)$ and were functionally more severe $(p<0.0001)$. The majority of younger patients $(64.96 \%)$ underwent anterior surgery, whereas the preferred approach in the elderly group was posterior $(58.62 \%$, $p<0.0001)$. Elderly patients had a greater number of decompressed levels than younger patients $(p<0.0001)$. At 24 months after surgery, younger patients achieved a higher postoperative mJOA $(p<0.0001)$ and a lower Nurick score $(p<0.0001)$ than elderly patients. After adjustments for patient and surgical characteristics, these differences in postoperative outcome scores decreased but remained significant.

Conclusions Older age is an independent predictor of functional status in patients with DCM. However, patients over 65 with DCM still achieve functionally significant improvement after surgical decompression.

\section{INTRODUCTION}

Currently, the global population is experiencing a shift in its age structure. According to the WHO, the proportion of the population over 60 years of age is projected to double from $11 \%$ in 2010 to $22 \%$ in $2050 .^{12}$ With this ageing of the population, clinicians worldwide will be required to manage an increasing number of spinal disorders related to advancing age, including degenerative cervical myelopathy (DCM).

DCM is a progressive, degenerative spine disease and the most common cause of spinal cord dysfunction in adults worldwide. ${ }^{3-6}$ It is caused by age-related alterations to the spinal axis including (1) degeneration of the facet joints, intervertebral discs and/or vertebral bodies; (2) hypertrophy of the ligamentum flavum; and (3) ossification of the longitudinal ligament (OPLL), all of which may chronically compress the spinal cord. Of patients with evidence of spinal degeneration, approximately one-quarter will develop symptoms of neurological impairment due to mechanical compression of the neural elements. ${ }^{7-9}$

When patients present with symptomatic myelopathy, surgery is effective at halting further deterioration and improving neurological outcomes, functional status and quality of life. ${ }^{10-12}$ However, there is controversy regarding whether surgical decompression is equally effective and safe in elderly patients as it is in younger patients. ${ }^{13-18}$ Several studies to date have identified age as a significant predictor of surgical outcome, including the recent prospective multicenter AOSpine CSM-North America and CSM-International studies. ${ }^{5} 1719$ In general, older patients have reduced recovery potential following surgery due to comorbidities, diminished physiological reserves and age-related changes to the spinal cord, including a decrease in the number of myelinated fibres in the corticospinal tracts and posterior funiculus. ${ }^{20-23}$ Furthermore, the elderly are likely to have more substantial degenerative pathology and may require a more complex surgery.

There are several methodological limitations and knowledge gaps in the current body of literature. These include (1) a lack of multicentre prospective studies with large sample sizes; (2) insufficient evidence reporting the association between age and quality of life (QOL) outcomes such as the 36-Item Short Form Health Survey (SF-36); and (3) a lack of statistical analyses appropriately adjusting for differences in baseline characteristics and surgical factors. 
The objective of this study is to compare clinical, functional and QOL outcomes between two age groups $(\geq 65,<65$ years) and to determine whether age is an independent predictor of outcome. In addition, this study aims to evaluate differences in demographics, comorbidities, management strategies and rates of perioperative complications between these two age groups. It is anticipated that these data will inform clinical decisionmaking older individuals with DCM.

\section{MATERIALS AND METHODS}

Subjects

Between October 2007 and January 2011, 479 patients with symptomatic DCM were prospectively enrolled in the AOSpine CSM-International study at 16 global institutions. Participating sites were either academic centres or high volume private practices and all had the resources necessary to conduct prospective clinical research, adequate subject availability and experienced research personnel. Investigators were orthopaedic surgeons or neurosurgeons who specialised in treating disorders of the spine.

Patients were asked to participate in this study if they were referred for surgical consultation and if they satisfied the following inclusion criteria: (1) aged 18 years or older; (2) presenting with symptomatic DCM with at least one clinical sign of myelopathy; (3) image-evidence of cervical spinal cord compression on MRI or CT; and (4) no previous cervical spine surgery. Patients were included in this study if they had myelopathy due to spondylosis, hypertrophy of the ligamentum flavum, OPLL, disc herniation, subluxation or a combination of these degenerative changes. Patients were excluded if they were asymptomatic or diagnosed with active infection, neoplastic disease, rheumatoid arthritis, ankylosing spondylitis or concomitant lumbar stenosis.

\section{Surgical techniques}

At their respective sites, all patients underwent surgical decompression of the cervical spinal cord. For each case, the attending surgeon decided what approach to use, the number of levels to decompress and whether or not to use fusion or instrumentation. Anterior surgeries included cervical discectomy and/or corpectomy with or without fusion. Patients treated posteriorly underwent either laminectomy with or without fusion or laminoplasty. A minority of patients was treated with a two-stage circumferential surgery.

\section{Data collection}

Extensive data were collected for each participating subject, including demographic information, disease causation, medical history and current comorbidities, symptomatology, surgical summary and level of impairment and disability. Each subject was neurologically examined at baseline and 24 months postoperatively and evaluated using a variety of functional and quality of life outcome measures, including the Neck Disability Index (NDI), SF-36, the Nurick and the modified Japanese Orthopaedic Association (mJOA) scales. In addition, each attending surgeon was required to record all adverse events throughout the study period. A central panel of investigators classified each event as related to surgery, related to myelopathy or unrelated. Perioperative complications were defined as surgery-related events occurring within 30 days of surgery.

\section{Quality assurance}

External research monitors performed on-site evaluations to ensure that the data were accurate, reliable and complete and that the study was conducted in accordance with the protocol. All data were transcribed into an electronic data capture system and were processed at the AOSpine clinical research network data management centre.

\section{Statistical analysis}

Our sample was divided into two age groups: a younger group (patients $<65$ years old) and an elderly group (patients $\geq 65$ ). Means \pm SDs were used to describe continuous variables and percentages were used to summarise categorical variables.

Patient demographics, baseline status and surgical factors were compared between the two age groups using an appropriate $t$ test for continuous variables and a $\chi^{2}$ test for categorical variables. Any variable that was significantly different $(p<0.05)$ between the younger and elderly patients was controlled for in our multivariate analysis.

A mixed model analytic approach was used to compare patient outcomes between the younger and elderly groups. The independent variable of the model was age and the dependent variable was postoperative outcome at 24 months (mJOA, Nurick, NDI, SF-36 physical component summary (PCS) and mental component summary (MCS)). Cases with missing data were not included in the analyses.

We first created an unadjusted model between age and surgical outcome (controlling for preoperative severity) and then developed two adjusted models that accounted for variations between the two age groups in (1) preoperative severity and other baseline characteristics and (2) both baseline demographics and surgical factors. These methods assessed whether any observed differences in outcome between the younger and elderly patients were due to other covariates or whether age is an independent predictor. Our adjusted models consisted of 6-8 predictors. As a rule of thumb, a well-powered statistical analysis requires 10 patients for each predictor evaluated. Our sample size of 479 patients (119 in elderly patients, 360 in younger patients) greatly exceeds the suggested criteria of $60-80$ patients.

\section{RESULTS}

From October 2007 to January 2011, 479 patients were enrolled in the CSM-International study at 16 global spine centres in four continents: $150(31.32 \%)$ from the Asia-Pacific region, 126 (26.30\%) from Europe, 123 (25.68\%) from North America and $80(16.70 \%)$ from Latin America. Of the 479 patients, $360(75.16 \%)$ were less than 65 years of age and comprised the 'younger' group, while 119 (24.84\%) were greater than or equal to 65 years and were placed in the 'elderly' group.

\section{Demographics}

Patients in the elderly group were $71.63 \pm 5.34$ years old (median 71 years), whereas those in the younger group were 51.32 \pm 8.77 years old (median 53 years) $(\mathrm{p}<0.0001$; table 1$)$. There were no significant differences in gender $(p=0.82)$ or duration of symptoms $(p=0.82)$ between the two age groups. The elderly patients had worse general preoperative health status as reflected by a significantly higher number of comorbidities $(p<0.0001)$ and comorbidity score $(p<0.0001)$. In addition, a greater percentage of elderly patients suffered from coexisting diabetes $(\mathrm{p}=0.0004)$, cardiovascular disease $(\mathrm{p}<0.0001)$ and rheumatological disorders $(p<0.001)$. The frequency of psychiatric comorbidities, namely depression and bipolar disease, was higher in the younger group, although this relationship did not reach statistical significance $(p=0.08)$. Elderly patients were functionally more impaired preoperatively based on the mJOA $(\mathrm{p}<0.0001)$ and Nurick $(\mathrm{p}<0.0001)$ scales and had a lower SF-36 PCS $(p=0.048)$. There were no significant differences between age groups with respect to the NDI or SF-36 MCS. 
Table 1 Demographics and baseline severity scores of younger ( $<65$ years) and elderly ( $\geq 65$ years) patients

\begin{tabular}{|c|c|c|c|}
\hline & Younger patients ( $<65$ years) & Elderly patients ( $\geq 65$ years) & $p$ Value \\
\hline \multicolumn{4}{|l|}{ Demographics } \\
\hline Age (years) & $51.32 \pm 8.77$ & $71.63 \pm 5.34$ & $<0.0001$ \\
\hline Gender (\%) & $65.00 \mathrm{M}, 35.00 \mathrm{~F}$ & $63.87 \mathrm{M}, 36.13 \mathrm{~F}$ & 0.82 \\
\hline Duration of symptoms (months) & $27.40 \pm 35.34$ & $25.96 \pm 32.68$ & 0.82 \\
\hline Smoker (\%) & $32.78 \mathrm{Y}, 67.22 \mathrm{~N}$ & $10.92 \mathrm{Y}, 89.08 \mathrm{~N}$ & $<0.0001$ \\
\hline Comorbidities (\%) & $53.76 \mathrm{Y}, 46.24 \mathrm{~N}$ & $78.15 Y, 21.85 \mathrm{~N}$ & $<0.0001$ \\
\hline Comorbidity score & $1.13 \pm 1.51$ & $2.15 \pm 2.13$ & $<0.0001$ \\
\hline Number of comorbidities & $1.00 \pm 1.25$ & $1.74 \pm 1.31$ & $<0.0001$ \\
\hline Diabetes (\%) & $9.44 \mathrm{Y}, 90.56 \mathrm{~N}$ & $21.85 \mathrm{Y}, 78.15 \mathrm{~N}$ & 0.0004 \\
\hline Cardiovascular (\%) & $36.49 \mathrm{Y}, 63.51 \mathrm{~N}$ & $64.71 \mathrm{Y}, 35.29 \mathrm{~N}$ & $<0.0001$ \\
\hline Respiratory (\%) & $7.54 \mathrm{Y}, 92.46 \mathrm{~N}$ & $12.61 \mathrm{Y}, 87.39 \mathrm{~N}$ & 0.09 \\
\hline Gastrointestinal (\%) & $15.08 \mathrm{Y}, 84.92 \mathrm{~N}$ & $15.13 \mathrm{Y}, 84.87 \mathrm{~N}$ & 0.99 \\
\hline Renal (\%) & $1.40 \mathrm{Y}, 98.60 \mathrm{~N}$ & $4.20 \mathrm{Y}, 95.80 \mathrm{~N}$ & 0.13 \\
\hline Psychiatric (\%) & $9.22 \mathrm{Y}, 90.78 \mathrm{~N}$ & $4.20 \mathrm{Y}, 95.80 \mathrm{~N}$ & 0.08 \\
\hline Rheumatological (\%) & $1.68 \mathrm{Y}, 98.32 \mathrm{~N}$ & $6.72 \mathrm{Y}, 93.28 \mathrm{~N}$ & $<0.001$ \\
\hline Neurological (\%) & $3.63 \mathrm{Y}, 96.37 \mathrm{~N}$ & $6.72 \mathrm{Y}, 93.28 \mathrm{~N}$ & 0.15 \\
\hline \multicolumn{4}{|l|}{ Baseline functional status } \\
\hline $\mathrm{mJOA}$ & $12.86 \pm 2.76$ & $11.41 \pm 2.89$ & $<0.0001$ \\
\hline Nurick & $3.16 \pm 1.21$ & $3.75 \pm 1.23$ & $<0.0001$ \\
\hline \multicolumn{4}{|l|}{ Baseline quality of life } \\
\hline Neck Disability Index & $37.52 \pm 19.59$ & $39.15 \pm 22.31$ & 0.70 \\
\hline SF36v2 Physical Functioning & $32.51 \pm 11.94$ & $28.47 \pm 12.18$ & $<0.001$ \\
\hline SF36v2 Role Limitation Physical & $29.46 \pm 10.65$ & $28.90 \pm 12.14$ & 0.24 \\
\hline SF36v2 Bodily Pain & $35.96 \pm 10.75$ & $38.05 \pm 12.52$ & 0.15 \\
\hline SF36v2 General Health & $41.16 \pm 10.36$ & $41.12 \pm 9.96$ & 0.91 \\
\hline SF36v2 Emotional Well-being & $38.35 \pm 12.93$ & $40.95 \pm 12.78$ & 0.06 \\
\hline SF36v2 Role Limitation Emotional & $31.68 \pm 14.27$ & $31.62 \pm 16.35$ & 0.93 \\
\hline SF36v2 Social Functioning & $35.98 \pm 12.86$ & $34.89 \pm 13.00$ & 0.41 \\
\hline SF36v2 Energy/Fatigue & $42.59 \pm 11.09$ & $43.56 \pm 11.16$ & 0.38 \\
\hline SF36v2 Physical Component Score & $34.69 \pm 9.03$ & $32.90 \pm 8.91$ & 0.048 \\
\hline SF36v2 Mental Component Score & $38.94 \pm 13.10$ & $40.79 \pm 12.94$ & 0.16 \\
\hline
\end{tabular}

Means were compared using the appropriate $t$ test and frequencies were compared using the $\chi^{2}$ test.

mJOA, modified Japanese Orthopaedic Association scale.

\section{Surgical factors}

The majority of younger patients (64.96\%) underwent anterior surgery, whereas the preferred approach in the elderly group was posterior $(58.62 \%) \quad(\mathrm{p}<0.0001$; table 2$)$. Of patients treated anteriorly, a greater percentage of elderly patients received a combined anterior discectomy and corpectomy (27.66\%) compared to younger patients $(12.83 \%$; $\mathrm{p}=0.01)$. A similar percentage of patients in both age groups were treated with a two-stage anteroposterior surgery (younger: 2.23\%, elderly: $2.52 \%, \mathrm{p}=1.00)$. Elderly patients, on average, had a

Table 2 Differences in surgical factors between younger and elderly patients

\begin{tabular}{|c|c|c|c|}
\hline & Younger patients (<65 years) & Elderly patients ( $\geq 65$ years) & $p$ Value \\
\hline Operative duration (min) & $176.21 \pm 80.45$ & $183.75 \pm 79.48$ & 0.17 \\
\hline Number of operated levels & $3.50 \pm 1.23$ & $4.14 \pm 1.30$ & $<0.0001$ \\
\hline Surgical approach (\%) (Anterior, Posterior) & $64.96,35.04$ & $41.38,58.62$ & $<0.0001$ \\
\hline Anterior surgeries (\%) & & & $0.01^{*}$ \\
\hline Discectomy & 85.84 & 70.21 & \\
\hline Corpectomy & 1.33 & 2.13 & \\
\hline Discectomy and corpectomy & 12.83 & 27.66 & \\
\hline Posterior surgeries (\%) & & & $0.96 t$ \\
\hline Laminectomy without fusion & 6.50 & 11.76 & \\
\hline Laminectomy with fusion & 58.54 & 52.94 & \\
\hline Laminoplasty & 34.96 & 35.29 & \\
\hline Number of stages (\%) (single or multiple) & $97.77,2.23$ & $97.48,2.52$ & 1.00 \\
\hline
\end{tabular}


greater number of decompressed levels (which most likely accounts for the increased rate of posterior surgery; $4.14 \pm 1.30$ ) than younger patients $(3.50 \pm 1.23)(\mathrm{p}<0.0001)$ but a similar operative duration (younger: $176.21 \pm 80.45 \mathrm{~min}$, elderly: 183.75 $\pm 79.48 \mathrm{~min}, \mathrm{p}=0.17)$.

\section{Outcomes}

Three hundred and eighty-nine patients (81.21\%) attended their 24-month follow-up appointment and were assessed using the mJOA ( $n=385$ for SF-36 PCS and MCS, $n=389$ for Nurick, $\mathrm{n}=324$ for NDI; table 3 ). The remaining 90 patients $(18.79 \%)$ withdrew from this study $(1.25 \%)$, did not attend their scheduled appointment $(15.87 \%)$ or died prior to their 24-month postoperative visit (1.67\%).

In both age groups, patients demonstrated significant improvements across all outcome measures. Younger patients, however, achieved a higher postoperative mJOA $(15.45,95 \%$ CI 15.18 to 15.72 ) and a lower Nurick score $(1.64,95 \%$ CI 1.48 to 1.81 ) than elderly patients (mJOA: $14.08,95 \% \mathrm{CI}$ 13.61 to $14.56, \mathrm{p}<0.0001$; Nurick: $2.44,95 \%$ CI 2.15 to 2.73 , $\mathrm{p}<0.0001)$. SF-36 PCS scores were also significantly higher in the younger group $(41.87,95 \%$ CI 40.73 to 43.00$)$ than in the elderly group $(39.36,95 \%$ CI 37.38 to $41.36, p=0.033)$. There were no significant differences in postoperative NDI or SF-36 MCS between age groups after controlling for preoperative severity.

Adjusted models were run to compare postoperative Nurick and mJOA scores between the two age groups, while controlling for differences in patient characteristics (preoperative severity, diabetes, cardiovascular disease, rheumatological disorders and comorbidity score). After adjustment, the differences in mJOA and Nurick scores between age groups remained significant (mJOA: $\mathrm{p}<0.0001$; Nurick: $\mathrm{p}=0.0002)$. The differences in SF-36 PCS between age groups became insignificant $(p=0.08)$.
A second set of adjusted models was created to further control for differences in surgical features between age groups, such as the approach (anterior, posterior or combined) and number of decompressed segments. Even after this adjustment, functional differences between the elderly and younger groups remained statistically significant (mJOA: $p<0.0001$, Nurick: $\mathrm{p}=0.0006$ ), although the difference between mean outcome scores across age groups decreased (Nurick: unadjusted $=-0.80$ $(-1.13$ to -0.46$)$, adjusted $=-0.63(95 \% \mathrm{CI}-0.99$ to -0.27$)$; mJOA: unadjusted $=1.36$ (95\% CI 0.81 to 1.92$)$, adjusted: 1.25 (95\% CI 0.68 to 1.82 ).

\section{Complications}

On average, elderly patients had a significantly longer length of postoperative hospital stay (12.99 \pm 13.56 days) than younger patients $(9.53 \pm 8.67$ days) $(\mathrm{p}=0.0086$; table 4$)$. There were no significant differences between the two age groups with respect to rates of perioperative complications $(p=0.47)$, C5 nerve root palsy $(p=0.58)$, superficial $(p=1.00)$ or deep $(p=0.15)$ infection, dysphagia $(p=0.80)$ or dural tear $(p=0.76)$. A greater percentage of elderly patients $(2.52 \%)$ experienced screw malposition in the perioperative period compared to younger patients $(0 \% ; \mathrm{p}=0.015)$. Rates of progression and perioperative worsening of myelopathy were similar across the two age groups.

\section{DISCUSSION}

This study represents the largest prospective analysis of the relative efficacy and safety of surgical decompression in younger and elderly patients. On the basis of our findings, younger patients have superior functional status and clinical outcomes at 24 months following surgery based on the mJOA and Nurick scales. This indicates that the elderly may not be able to translate neurological improvements into functional recovery as effectively as younger patients. Potential explanations for this

Table 3 Functional status and quality of life at 24 months following surgery

\begin{tabular}{|c|c|c|c|c|}
\hline Outcome & Younger patients (<65 years) & Elderly patients ( $\geq 65$ years) & Difference & $\mathrm{p}$ Value \\
\hline \multicolumn{5}{|l|}{ Unadjusted* } \\
\hline $\mathrm{mJOA}$ & $15.45(15.18,15.72)$ & $14.08(13.61,14.56)$ & $1.36(0.81,1.92)$ & $<0.0001$ \\
\hline Nurick & $1.64(1.48,1.81)$ & $2.44(2.15,2.73)$ & $-0.80(-1.13,-0.46)$ & $<0.0001$ \\
\hline NDI & $23.83(21.76,25.90)$ & $23.99(20.51,27.46)$ & $-0.16(-4.20,3.89)$ & 0.94 \\
\hline SF-36v2 PCS & $41.87(40.73,43.00)$ & $39.36(37.38,41.36)$ & $2.50(0.21,4.80)$ & 0.033 \\
\hline SF-36v2 MCS & $47.34(45.96,48.72)$ & $46.72(44.31,49.13)$ & $1.41(-2.16,3.40)$ & 0.66 \\
\hline \multicolumn{5}{|c|}{ Adjustment Model $1 \dagger$} \\
\hline $\mathrm{mJOA}$ & $14.02(13.23)$ & $12.72(11.86,13.58)$ & $1.31(0.73,1.87)$ & $<0.0001$ \\
\hline Nurick & $2.52(2.02,3.01)$ & $3.20(2.67,3.74)$ & $-0.69(-1.04,-0.33)$ & 0.0002 \\
\hline NDI & $30.63(24.16,37.10)$ & $29.61(22.52,36.70)$ & $1.02(-3.96,6.01)$ & 0.69 \\
\hline SF-36v2 PCS & $38.02(34.41,41.63)$ & $35.90(31.96,39.83)$ & $1.21(-0.25,4.50)$ & 0.080 \\
\hline SF-36v2 MCS & $46.70(41.87,51.54)$ & $47.71(42.45,52.97)$ & $-1.01(-4.19,2.17)$ & 0.53 \\
\hline \multicolumn{5}{|c|}{ Adjustment Model 2‡ } \\
\hline mJOA & $13.80(12.86,14.74)$ & $12.55(11.55,13.55)$ & $1.25(0.68,1.82)$ & $<0.0001$ \\
\hline Nurick & $2.58(2.00,3.17)$ & $3.22(2.59,3.85)$ & $-0.63(-0.99,-0.27)$ & 0.0006 \\
\hline NDI & $27.79(20.16,35.42)$ & $26.84(18.60,35.07)$ & $0.95(-4.08,5.99)$ & 0.71 \\
\hline SF-36v2 PCS & $38.87(34.64,43.10)$ & $36.91(32.37,41.44)$ & $1.96(-0.48,4.40)$ & 0.16 \\
\hline SF-36v2 MCS & $48.64(43.01,54.26)$ & $48.92(42.89,54.96)$ & $-0.29(-3.54,2.96)$ & 0.86 \\
\hline
\end{tabular}


Table 4 Length of hospital stay and perioperative complications

\begin{tabular}{lcll}
\hline & $\begin{array}{l}\text { Younger } \\
\text { patients } \\
(<65 \text { years) }\end{array}$ & $\begin{array}{l}\text { Elderly } \\
\text { patients } \\
\text { ( } \geq 65 \text { years) }\end{array}$ & p Value \\
\hline Length of hospital stay (days) & $9.53 \pm 8.67$ & $12.99 \pm 13.56$ & $<0.01$ \\
Perioperative complications (\%) & 15.56 & 18.49 & NS \\
Pseudoarthrosis (\%) & 0.28 & 0.84 & NS \\
Hardware failure (\%) & 0.28 & - & NS \\
Screw malposition (\%) & - & 2.52 & 0.015 \\
Graft dislodgement (\%) & 0.28 & - & NS \\
Graft pain (\%) & 0.28 & - & NS \\
C5 palsy (\%) & 1.11 & - & NS \\
New neck pain (\%) & 0.28 & 0.84 & NS \\
Dural tear (\%) & 2.78 & 3.36 & NS \\
Superficial infection (\%) & 2.22 & 1.68 & NS \\
Deep infection (\%) & 0.28 & 1.68 & NS \\
Dysphagia (\%) & 4.17 & 5.04 & NS \\
Dysphonia (\%) & 0.56 & 0.84 & NS \\
Perioperative worsening of & 0.83 & - & NS \\
myelopathy (\%) & & & \\
Progression of myelopathy (\%) & 0.28 & - & NS \\
New radiculopathy (\%) & 0.28 & 1.68 & NS \\
Cardiopulmonary (\%) & 0.56 & - & NS \\
DVT (\%) & - & 0.84 & NS \\
Other (\%) & 2.22 & 5.04 & NS \\
\hline Means were compared using the appropriate $t$ test and frequencies were compared \\
using the $\chi^{2}$ test. \\
DVT, deep vein thrombosis; NS: not significant. & & \\
& & &
\end{tabular}

discrepancy between age groups include that the elderly (1) experience age-related changes in their spinal cord, including a decrease in $\gamma$-motor neurons, synaptic and dendritic elements, number of anterior horn cells and number of myelinated fibres in the corticospinal tract and posterior funiculus; ${ }^{20} 21$ (2) may have unassociated comorbidities that may impede their ability to perform the simple tasks required for the mJOA, such as locomotor diseases (hip and knee osteoarthritis), sarcopenia, diabetic neuropathy or urinary incontinence due to benign prostatic hypertrophy; ${ }^{16} 24$ (3) have reduced physiological reserves and, as a result, are less tolerant to physical assault such as that represented by surgery; ${ }^{25} 26$ and (4) may have substantial degenerative pathology that may require greater decompression and a more complex surgery. Surgeons, however, should not discriminate on the basis of age but should rather use this information during the surgical consent discussion to manage their patients' expectations and explain the relative risks and benefits of the procedure.

Interestingly, there were no significant differences in patientreported outcomes (NDI and SF-36) between age groups. This result indicates that a lower functional status translates to equivalent QOL in the elderly compared to younger patients. This finding is significant as cost-utility analyses typically explore the effectiveness of an intervention in terms of SF-6D utility values derived from SF-36 scores. $^{27}$ In addition, there were no significant differences in rates of overall perioperative or neurological complications between age groups.

This study also evaluated differences in baseline demographics and surgical strategies between age groups as these factors could also influence outcome. Unsurprisingly, elderly patients not only had more severe functional impairment preoperatively, but also had a higher comorbidity score and an increased frequency of diabetes, cardiovascular and rheumatological disorders. With respect to surgical factors, the elderly had a greater number of decompressed levels, were more often treated posteriorly and, if operated on anteriorly, were more likely to receive a combined discectomy and corpectomy. These differences confirm that the elderly may have more substantial degenerative pathology and may require a more extensive surgery. All of these factors could potentially explain the discrepancies in recovery potential between the younger and elderly patients as hypothesised earlier; however, after adjustment for these characteristics, differences in functional outcomes between the age groups were still significant. This allows us to conclude that age is an independent predictor of neurological outcome and that the elderly most likely have reduced recovery due to alterations in the composition of their spinal cord and diminished physiological reserves. However, given that (1) the absolute change in mJOA was still substantial and in excess of the MCID; ${ }^{28}$ (2) the quality of life between the elderly and younger patients was not significantly different; and (3) complication rates were similar between age groups despite worse preoperative health status in the elderly, surgery remains an effective treatment option for patients at an advanced age.

Our results must be interpreted in the context of the existing literature. We conducted a literature search to identify studies that examined the predictive value of age using a well-powered multivariate analysis. Results differed depending on what measurement was used to evaluate outcome.

\section{JOA recovery rate}

Fourteen studies evaluated the association between a patient's JOA recovery rate and his/her age. Recovery rate was calculated using the following equation developed by Hirabayashi: (postoperative JOA-preoperative JOA)/(17-preoperative JOA) $\times 100 \%$. $^{29}$ Three studies dichotomised the recovery rate and defined an 'excellent' outcome as a recovery rate $\geq 50 \%$ and a 'fair' outcome as a recovery rate $<50 \% .^{14} 30 \quad 31$ Yamazaki et $a^{14}$ and Naruse et al ${ }^{31}$ reported no significant difference in age between patients who achieved an excellent outcome and those who did not. In the study by Kim et al, ${ }^{30}$ however, the interaction of diabetes and old age increased the patient's risk of a poor surgical outcome (OR $2.21,1.15$ to 4.23 ).

Seven studies reported that older patients had a less favourable surgical outcome based on the JOA recovery rate..$^{52-37}$ Chen et $a l^{31}$ aimed to examine the impact of T2-SI on surgical prognosis and identified a significant association between patient age and recovery rate $(\mathrm{p}=0.037)$. Fujimura et $a l^{5}$ and Kato et $a l^{33}$ explored predictors of recovery at the short-term (1 year) and long-term follow-up: age was a significant predictor of outcome at 5 years postoperative in both studies. In a study by Koyanagi et $a l,{ }^{34}$ patients were divided into three groups depending on whether their primary diagnosis was CSM, OPLL or disc herniation. On the basis of univariate analysis, age was significantly correlated with the JOA recovery rate in patients with OPLL and cervical disc herniation but not in patients with CSM. However, in multivariate analysis, age was deemed an insignificant predictor of recovery rate in all three forms of DCM. Finally, three studies developed linear regression equations relating a combination of significant clinical and imaging variables to recovery rate. All three equations included age as a predictor. $^{35-37}$ In contrast, four studies could not identify a significant association between age and JOA recovery rate. ${ }^{38-41}$

\section{Postoperative mJOA/JOA score}

Seven studies used postoperative mJOA or JOA as the primary outcome measure. Of these, five reported an insignificant 
association between age and surgical outcome. ${ }^{11} 24384243$ In a study by Furlan et $a l,{ }^{44}$ age was significantly correlated with mJOA score at 6 months $\left(\mathrm{R}^{2}=0.287, \mathrm{p}<0.0001\right)$ and 12 months $\left(\mathrm{R}^{2}=0.185, \mathrm{p}=0.0003\right)$ postoperatively. In multivariate analysis, age was also a significant predictor of $\mathrm{mJOA}$ at 1 year $(\mathrm{p}=0.01)$. Morio et $a l^{37}$ constructed a regression model using a continuous JOA score as the outcome variable and included age as a predictor.

\section{Nurick scale}

In three studies, the Nurick score was dichotomised: a 'poor' neurological outcome was defined as either no change or a decrease in the Nurick grade, and a 'good' neurological outcome as an increase of at least one Nurick grade. ${ }^{45-47}$ In studies by Choi $e t a l^{45}$ and Rajshekar and Kumar, ${ }^{46}$ age was not a significant predictor of outcome. However, according to Suri et $a l,{ }^{47}$ patients in the $<40$ age group were 2.17 times more likely to exhibit improvement on the Nurick scale than patients aged $40-60$ years $(\mathrm{p}<0.001)$. In a fourth study, Furlan et $a l^{44}$ identified a significant association between the Nurick score at 1 year and age $(p=0.015)$.

It is evident that there is controversy in the literature as to whether age is a significant predictor of outcome. This study helps to confirm that, although surgery is effective for the elderly, these patients are less effective at translating neurological improvements to functional recovery. Given that our study is a prospective cohort study with a $\geq 80 \%$ follow-up rate, these results should be considered as a strong contribution to the overall body of evidence.

\section{Strengths and limitations}

Since patients were prospectively enrolled at 16 global sites, the findings of this study are likely to be more generalisable and externally valid than findings from single-centre studies. The large number of recruitment sites allowed us to evaluate outcomes for approximately 500 patients. Of these, 119 were over 65 years of age and categorised as 'elderly'; this reflects a cohort size that is larger than the majority of previous studies. In addition, we evaluated outcome using four different measurement tools, allowing for a complete and comprehensive assessment of surgical outcomes in patients with DCM.

This study has several limitations. First, a 16\% attrition rate was observed at the 12-month time point. Second, a standardised surgical protocol was not utilised across centres and the approach, number of decompressed levels and whether or not to use instrumentation and fusion was left to the discretion of the attending surgeon. However, the same goal of spinal cord decompression was achieved in all cases. Finally, we arbitrarily defined 65 as the cut-off between the younger and elderly patients. However, in support of the chosen cut-off, in a survey of AOSpine International members, 65 years was deemed as the threshold age above which there is a significant negative impact on surgical outcome. ${ }^{48}$ Furthermore, 65 is recognised as the retirement age and has also been used as a cut-off in previous DCM studies. ${ }^{14} 4950$

\section{CONCLUSION}

Our findings indicate that surgical decompression results in superior functional status in younger patients compared with elderly patients and confirms that the elderly are less effective at translating neurological recovery into functional improvements. In contrast, there were no differences in quality of life outcomes between age groups, indicating that the elderly and younger patients have similar perceptions of their disability despite significant differences in functional status. After adjustment of key demographic characteristics and surgical factors, the association between age and functional outcomes was still statistically significant; age is therefore an independent predictor of surgical outcome.

\section{Author affiliations}

${ }^{1}$ Department of Surgery, Division of Neurosurgery and Spinal Program, University of Toronto, Toronto Western Hospital, Toronto, Ontario, Canada

${ }^{2}$ Department of Orthopedic Surgery, Nagoya University Graduate School of Medicine, Nagoya, Japan

${ }^{3}$ Institute of Medical Science, University of Toronto, Toronto, Ontario, Canada ${ }^{4}$ Department of Orthopaedic Surgery, Keio University School of Medicine, Tokyo, Japan

${ }^{5}$ Department of Health Services, University of Washington, Seattle, Washington, USA ${ }^{6}$ Department Neurosurgery, University of Kansas, Kansas City, Kansas, USA ${ }^{7}$ Department of Neurosurgery, Radboud University Medical Center, Nijmegen, Netherlands

${ }^{8}$ Faculty of Medicine, University of Sao Paulo, Ribeirão Preto, Brazil

${ }^{9}$ Department of Neurosurgery, All India Institute of Medical Sciences, New Delhi, Delhi, India

${ }^{10}$ Department of Orthopedics, Third Military Medical University, Chongqing, China

Acknowledgements This study was sponsored by AOSpine International.

Contributors HN, LAT, NN and AN were responsible for analysis of data, preparation of manuscript, approval of final manuscript. BK and MGF were responsible for design and conception of study, analysis of data, preparation of manuscript and approval of final manuscript. PMA, RB, SK and QZ were responsible for data collection, preparation of manuscript, approval of final manuscript. HD was responsible for data collection, analysis of data, preparation of manuscript and approval of final manuscript.

\section{Competing interests None declared.}

Ethics approval University Health Network Research Ethics Board (UHN-REB) and other boards at other sites as appropriate to a multicentre study.

Provenance and peer review Not commissioned; externally peer reviewed.

Open Access This is an Open Access article distributed in accordance with the Creative Commons Attribution Non Commercial (CC BY-NC 4.0) license, which permits others to distribute, remix, adapt, build upon this work non-commercially, and license their derivative works on different terms, provided the original work is properly cited and the use is non-commercial. See: http://creativecommons.org/ licenses/by-nc/4.0/

\section{REFERENCES}

1 Muramatsu N, Akiyama H. Japan: super-aging society preparing for the future. Gerontologist 2011;51:425-32.

2 Ortman JM, Velkoff VA, Hogan H. An aging nation: the older population in the United States. Proc. Economics and Statistics Administration, US Department of Commerce, 2014

3 Young WF. Cervical spondylotic myelopathy: a common cause of spinal cord dysfunction in older persons. Am Fam Physician 2000;62:1064-73.

4 Kalsi-Ryan S, Karadimas SK, Fehlings MG. Cervical spondylotic myelopathy the clinical phenomenon and the current pathobiology of an increasingly prevalent and devastating disorder. Neuroscientist 2013;19:409-21.

5 Fujimura Y, Nishi Y, Chiba K, et al. Multiple regression analysis of the factors influencing the results of expansive open-door laminoplasty for cervical myelopathy due to ossification of the posterior longitudinal ligament. Arch Orthop Trauma Surg 1998;117:471-4.

6 Nouri A, Tetreault L, Singh A, et al. Degenerative cervical myelopathy: epidemiology, genetics and pathogenesis. Spine (Phila Pa 1976) 2015;40:E675-93.

7 Bednarik J, Kadanka Z, Dusek L, et al. Presymptomatic spondylotic cervical cord compression. Spine 2004:29:2260-9.

8 Hughes J, Brownell B. Necropsy observations on the spinal cord in cervical spondylosis. Riv Patol Nerv Ment 1965;86:196

9 Irvine D, Foster J, Newell $D$, et al. Prevalence of cervical spondylosis in a general practice. Lancet 1965;285:1089-92.

10 Fehlings MG, Wilson JR, Kopjar B, et al. Efficacy and safety of surgical decompression in patients with cervical spondylotic myelopathy results of the AOSpine North America prospective multi-center study. J Bone Joint Surg Am 2013;95:1651-8.

11 Iwasaki M, Kawaguchi $Y$, Kimura T, et al. Long-term results of expansive laminoplasty for ossification of the posterior longitudinal ligament of the cervical spine: more than 10years follow up. J Neurosurg 2002;96:180-9.

12 Chiba K, Ogawa Y, Ishii K, et al. Long-term results of expansive open-door laminoplasty for cervical myelopathy- average 14-year follow-up study. Spine 2006:31:2998-3005.

13 Yoon ST, Raich A, Hashimoto RE, et al. Predictive factors affecting outcome after cervical laminoplasty. Spine (Phila Pa 1976) 2013;38(22 Suppl 1):S232-52. 
14 Yamazaki T, Yanaka K, Sato H, et al. Cervical spondylotic myelopathy: surgical results and factors affecting outcome with special reference to age differences. Neurosurgery 2003;52:122-6.

15 Masaki Y, Yamazaki M, Okawa A, et al. An analysis of factors causing poor surgical outcome in patients with cervical myelopathy due to ossification of the posterior longitudinal ligament: anterior decompression with spinal fusion versus laminoplasty. J Spinal Disord Tech 2007;20:7-13.

16 Machino M, Yukawa Y, Hida $T$, et al. Can elderly patients recover adequately after laminoplasty?: a comparative study of 520 patients with cervical spondylotic myelopathy. Spine (Phila Pa 1976) 2012;37:667-71.

17 Nakashima H, Yukawa Y, Ito K, et al. Prediction of lower limb functional recovery after laminoplasty for cervical myelopathy: focusing on the 10-s step test. Eur Spine J 2012:21:1389-95.

18 Lu J, Wu X, Li Y, et al. Surgical results of anterior corpectomy in the aged patients with cervical myelopathy. Eur Spine J 2008;17:129-35.

19 Tetreault L, Fehlings MG, Kopjar B, et al. A clinical prediction rule for clinical outcomes in patients undergoing surgery for degenerative cervical myelopathy: analysis of an International AOSpine Prospective Multicenter Dataset of 771 Subjects. Spine J 2013;13:S3.

20 Terao S, Sobue G, Hashizume Y, et al. Age-related changes of the myelinated fibers in the human corticospinal tract: a quantitative analysis. Acta neuropathol 1994;88:137-42.

21 Terao S, Sobue G, Hashizume $Y$, et al. Age-related changes in human spinal ventra horn cells with special reference to the loss of small neurons in the intermediate zone: a quantitative analysis. Acta Neuropathol 1996;92:109-14.

22 Marcantonio $\mathrm{E}$, Goldman L, Rohde LE, et al. Impact of age on perioperative complications and length of stay in patients undergoing noncardiac surgery. Ann Intern Med 2001;134:637-43.

23 Daubs MD, Lenke LG, Cheh $G$, et al. Adult spinal deformity surgery: complications and outcomes in patients over age 60. Spine 2007;32:2238-44.

24 Tanaka J, Seki N, Tokimura F, et al. Operative results of canal-expansive laminoplasty for cervical spondylotic myelopathy in elderly patients. Spine (Phila Pa 1976) 1999:24:2308-12.

25 Clegg A, Young J, lliffe S, et al. Frailty in elderly people. Lancet 2013;381:752-62.

26 Partridge JS, Harari D, Dhesi JK. Frailty in the older surgical patient: a review. Age Ageing 2012;41:142-7

27 Fehlings MG, Jha NK, Hewson SM, et al. Is surgery for cervical spondylotic myelopathy cost-effective? A cost-utility analysis based on data from the AOSpine North America prospective CSM study. J Neurosurg Spine 2012;17:89-93.

28 Tetreault $L$, Nouri A, Cote $P$, et al. The minimum clinically important difference of the modified Japanese Orthopaedic Association scale in patients with degenerative cervical myelopathy. Spine (Phila Pa 1976) June 4, 2015 (accepted).

29 Hirabayashi K, Miyakawa J, Satomi K, et al. Operative results and postoperative progression of ossification among patients with ossification of cervical posterior longitudinal ligament. Spine (Phila Pa 1976) 1981;6:354-64.

$30 \mathrm{Kim} \mathrm{HJ}$, Moon SH, Kim HS, et al. Diabetes and smoking as prognostic factors after cervical laminoplasty. J Bone Joint Surg Br 2008;90:1468-72.

31 Naruse T, Yanase $\mathrm{M}$, Takahashi $\mathrm{H}$, et al. Prediction of clinical results of laminoplasty for cervical myelopathy focusing on spinal cord motion in intraoperative ultrasonography and postoperative magnetic resonance imaging. Spine (Phila Pa 1976) 2009:34:2634-41.

32 Chen CJ, Lyu RK, Lee ST, et al. Intramedullary high signal intensity on T2-weighted MR images in cervical spondylotic myelopathy: prediction of prognosis with type of intensity. Radiology 2001;221:789-94.
33 Kato Y, Iwasaki M, Fuji T, et al. Long-term follow-up results of laminectomy for cervical myelopathy caused by ossification of the posterior longitudinal ligament. J Neurosurg 1998;89:217-23.

34 Koyanagi T, Hirabayashi K, Satomi K, et al. Predictability of operative results of cervical compression myelopathy based on preoperative computed tomographic myelography. Spine (Phila Pa 1976) 1993;18:1958-63.

35 Zhang $P$, Shen $Y$, Zhang $Y Z$, et al. Significance of increased signal intensity on MRI in prognosis after surgical intervention for cervical spondylotic myelopathy. J Clin Neurosci 2011;18:1080-3.

36 Zhang $Y Z$, Shen $Y$, Wang LF, et al. Magnetic resonance $T 2$ image signal intensity ratio and clinical manifestation predict prognosis after surgical intervention for cervical spondylotic myelopathy. Spine (Phila Pa 1976) 2010;35:E396-9.

37 Morio $Y$, Teshima R, Nagashima $H$, et al. Correlation between operative outcomes of cervical compression myelopathy and mri of the spinal cord. Spine (Phila Pa 1976) 2001;26:1238-45.

38 Iwasaki M, Okuda S, Miyauchi A, et al. Surgical strategy for cervical myelopathy due to ossification of the posterior longitudinal ligament: Part 1: Clinical results and limitations of laminoplasty. Spine (Phila Pa 1976) 2007;32:647-53.

39 Okada Y, Ikata T, Yamada $\mathrm{H}$, et al. Magnetic resonance imaging study on the results of surgery for cervical compression myelopathy. Spine (Phila Pa 1976) 1993;18:2024-9.

40 Shin JJ, Jin BH, Kim KS, et al. Intramedullary high signal intensity and neurological status as prognostic factors in cervical spondylotic myelopathy. Acta neurochirurgica 2010;152:1687-94.

41 Wada E, Yonenobu K, Suzuki S, et al. Can intramedullary signal change on magnetic resonance imaging predict surgical outcome in cervical spondylotic myelopathy? Spine (Phila Pa 1976) 1999;24:455-61; discussion 62

42 Chibbaro S, Benvenuti L, Carnesecchi S, et al. Anterior cervical corpectomy for cervical spondylotic myelopathy: experience and surgical results in a series of 70 consecutive patients. J Clin Neurosci 2006;13:233-8.

43 Uchida K, Nakajima H, Sato R, et al. Multivariate analysis of the neurological outcome of surgery for cervical compressive myelopathy. J Orthop Sci 2005;10:564-73.

44 Furlan JC, Kalsi-Ryan S, Kailaya-Vasan A, et al. Functional and clinical outcomes following surgical treatment in patients with cervical spondylotic myelopathy: a prospective study of 81 cases: clinical article. J Neurosurg Spine 2011;14: 348-55.

45 Choi S, Lee SH, Lee JY, et al. Factors affecting prognosis of patients who underwent corpectomy and fusion for treatment of cervical ossification of the posterior longitudinal ligament: analysis of 47 patients. J Spinal Disord Tech 2005;18:309-14

46 Rajshekhar V, Kumar GS. Functional outcome after central corpectomy in poor-grade patients with cervical spondylotic myelopathy or ossified posterior longitudinal ligament. Neurosurgery 2005;56:1279-85.

47 Suri A, Chabbra RP, Mehta VS, et al. Effect of intramedullary signal changes on the surgical outcome of patients with cervical spondylotic myelopathy. Spine J 2003;3:33-45.

48 Tetreault LA, Nouri A, Singh A, et al. Predictors of outcome in patients with cervical spondylotic myelopathy undergoing surgical treatment: a survey of members from AOSpine International. World Neurosurg 2014;81:623-33.

49 Nagata K, Ohashi T, Abe J, et al. Cervical myelopathy in elderly patients: clinical results and MRI findings before and after decompression surgery. Spinal cord 1996;34:220-6.

50 Hirai 0, Kondo A, Aoyama I, et al. [Anterior decompression surgery of aged patients with cervical myelopathy]. No Shinkei Geka 1991;19:1017-23. 